Article

\title{
Properties of Polylactic Acid Reinforced by Hydroxyapatite Modified Nanocellulose
}

\author{
Jianxiao Lu 1,2, Chuanyue Sun 1,2, Kexin Yang 1,2, Kaili Wang 1,2, Yingyi Jiang 1,2, \\ Rogers Tusiime 1,2 1 , Yun Yang 1,2, Fan Fan ${ }^{1,2}$, Zeyu Sun ${ }^{1,2}$, Yong Liu 1,2, Hui Zhang 1,2,*, \\ Keqing Han ${ }^{1,2}$ (D) and Muhuo Yu 1,2,* \\ 1 State Key Laboratory for Modification of Chemical Fibers and Polymer Materials, College of Materials \\ Science and Engineering, Donghua University, Shanghai 201620, China; ljxstayreal@foxmail.com (J.L.); \\ woai82dian@protonmail.com (C.S.); kexin_yang@163.com (K.Y.); 18616146552@163.com (K.W.); \\ 13888665350@163.com (Y.J.); 317001@mail.dhu.edu.cn (R.T.); 2180462@mail.dhu.edu.cn (Y.Y.); \\ 18256787163@163.com (F.F.); sunzeyu@dhu.edu.cn (Z.S.); liuyong@dhu.edu.cn (Y.L.); \\ hankeqing@dhu.edu.cn (K.H.) \\ 2 Shanghai Key Laboratory of Lightweight Structural Composites, Shanghai 201620, China \\ * Correspondence: zhanghui@dhu.edu.cn (H.Z.); yumuhuo@dhu.edu.cn (M.Y.)
}

Received: 23 May 2019; Accepted: 4 June 2019; Published: 6 June 2019

\begin{abstract}
Polylactic acid (PLA) is one of the most promising bio-based materials, but its inherent hydrophobicity limits its application. Although nanocellulose (NCC) is a desirable reinforcement for PLA, the poor interface compatibility between the two has been a challenge. In this work, hydroxyapatite (HAP) modified NCC was prepared, and the obtained NCC/HAP reinforcement was used to prepare PLA/NCC-HAP composites. Different ratios of NCC to HAP were studied to explore their effects on the mechanical and thermodynamic properties of the composites. When the ratio of NCC to HAP was 30/70, the tensile strength and tensile modulus of the composite film reached 45.6 $\mathrm{MPa}$ and 2.34 GPa, respectively. Thermogravimetric analysis results indicate that thermal stability of the composites was significantly improved compared with pure PLA, reaching $346.6{ }^{\circ} \mathrm{C}$. The above revelations show that NCC/HAP significantly improved the interface compatibility with PLA matrix.
\end{abstract}

Keywords: nanocellulose; hydroxyapatite; polylactic acid; compatibility

\section{Introduction}

Since polylactic acid (PLA) was approved by the United States Food and Drug Administration (FDA) in 1970, PLA has emerged as one of the most promising biopolymers. Nowadays, numerous research efforts have been dedicated to developing environmentally-friendly materials to replace the original petroleum-based materials and expand various biomedical applications, like drug delivery and tissue engineering [1-3]. Polylactic acid has the advantages of biocompatibility and biodegradability, high strength, high modulus and good optical transparency [4]. Its applications include, but are not limited to, medical, fiber and textiles, packaging, plastic cultivation, environmental restoration, paint, cigarette filters, 3D printing and space exploration parts. However, polylactic acid has obvious disadvantages such as inherent hydrophobicity, low crystallinity and poor heat resistance, which hinders its extensive application and development [5]. Blending is a simple and effective way to modify the properties of polymers [6-8]. The use of fibers or fillers to enhance properties is the primary means of improving performance of polylactic acid [9]. Among the fibers or fillers, nanocellulose (NCC) is a biocompatible and biodegradable biopolymer, which has become one of the most popular reinforcing materials for polylactic acid.

Cellulose is the most abundant biomass material in nature and derives from corn, paddy crops, natural vegetation, algae and bacteria. Extracted from cellulose, nanocellulose and nanocellulose-derived 
materials are variously available, like film, building materials, medicines and food, due to its hydrophilicity, biodegradability and chemical modification ability [10-15]. Now, the nitro-oxidation method is a common method to prepare nanocellulose, and the water purification treatment is a popular application [16-19]. Also, based on the special physicochemical properties of nanomaterials, nanocellulose is a promising reinforced material for polylactic acid to improve the mechanical properties [20]. However, it is still a challenge to uniformly distribute the nanocellulose in polylactic acid matrix because of the strong hydrophilicity of nanocellulose and the hydrophobicity of polylactic acid. Research on the physical and chemical modification of nanocellulose to enhance the interfacial compatibility between nanocellulose and polylactic acid has been reported [21-26]. However, the treatment of inorganic particles and organic particle fillers still accounts for the majority [27-32].

The treatment of inorganic particle to obtain nanocellulose/inorganic particle composites is one of the most commonly used methods for nanocellulose modification [33]. Mahmoudian et al. [34] used a wet spinning method to prepare a regenerated cellulose/montmorillonite nanocomposite fiber with an environmentally friendly ionic liquid. The results showed that when the mass fraction of montmorillonite was $6 \%$, the composite had good dispersion, and the thermal stability and mechanical properties of the composite were improved. Garusinghe et al. [35] developed a novel composite material that disperses montmorillonite into nanocellulose and achieves low water vapor permeability. However, the compatibility of montmorillonite was so poor that the prepared composites cannot meet the practical application requirements. Also, the modification of montmorillonite still had many complications such as high price, large dosage, intricate modification process and low efficiency. The same handicaps were observed with carbon nanotubes [36] and graphene oxide [37].

Hokkanen et al. [38] prepared a hydroxyapatite-bentonite-clay-nanocellulose composite as an adsorbent to remove $\mathrm{Ni}^{2+}, \mathrm{Cd}^{2+}$ and $\mathrm{PO}_{4}{ }^{3-}$ from aqueous solutions. Niamsap et al. [39] synthesized bacterial nanocellulose/hydroxyapatite/cellulose nanocrystal composites which can be used in tissue scaffolds in the medical field because of the biocompatibility. The above works used hydroxyapatite (HAP) to prepare nanocellulose composites, expanding the application of the composites. However, there was no research regarding the influence of different ratios of NCC to HAP on properties of the composites.

PLA has inherent hydrophobicity, while both NCC and HAP are hydrophilic. Herein, we hope to use the hydrophilicity of the two to reduce the hydrophobicity of PLA for more expanding application. In addition, due to biodegradability, biocompatibility and high strength, both NCC and HAP meet current environmental requirements and overcome the shortcomings of PLA such as, low crystallinity and heat resistance, improving mechanical properties [40]. For NCC, HAP and NCC/HAP nanofillers, the microscopic interface compatibility can be observed indirectly from macroscopic performance, such as tensile test. Only NCC and only HAP commonly need modification before enhancing PLA, while for NCC/HAP, itself is one method of modification. NCC is usually used to reinforce the PLA matrix. However, modification is necessary to coordinate the interfacial compatibility. In this work, NCC was modified by HAP and its surface is changed from smooth to rough, which increased the contact area with polymer matrix. When the NCC/HAP was blended with PLA, the NCC/HAP with a rough surface operated like an anchor to the PLA matrix, which contributed to the increase of the composite mechanical properties [41]. Therefore, NCC/HAP with different ratios was prepared to reinforce PLA. Properties of the obtained PLA/NCC-HAP composites were systematically investigated. The results show that NCC/HAP is a good reinforcing material for PLA, enhances the interfacial compatibility and improves the mechanical and thermodynamic properties of the composites.

\section{Materials and Methods}

\subsection{Materials}

Cotton pulp (DP: 350) was obtained from Jiangsu, China. Analytical reagent of sulfuric acid, sodium hydroxide, calcium nitrate tetrahydrate, diammonium phosphate, ethanol and chloroform 
were purchased from Sinopharm Chemical Reagent Co. Ltd., Shanghai, China. Polylactic acid (3052D) was produced by NatureWorks LLC, Blair, NE, USA. All the reagents were used as received without further purification.

\subsection{Preparation of NCC}

The cotton pulp was pulverized into cotton cellulose using a pulverizer. The cellulose and the sulfuric acid solution ( $64 \%$ by weight) were mixed at a ratio of $1: 20 \mathrm{~g} / \mathrm{mL}$ (cellulose: sulfuric acid solution) and stirred in a water bath at $50^{\circ} \mathrm{C}$ for $1 \mathrm{~h}$. The suspension was diluted 10 -fold with deionized water to stop the reaction and stood for $24 \mathrm{~h}$. The dilution was then centrifuged at 10,000 rpm multiple times to concentrate the cellulose and remove excess acid. The precipitated material was rinsed with distilled water and centrifuged again. Then the procedure repeated. Then sodium hydroxide was added to adjust the $\mathrm{pH}$ to 7 . The neutralized suspension was sufficiently dispersed by an ultrasonic cell disrupter, and finally freeze-dried to obtain nanocellulose [42].

\subsection{Preparation of NCC-HAP}

An appropriate amount of nanocellulose was thoroughly dispersed in deionized water. Calcium nitrate tetrahydrate and diammonium hydrogen phosphate were added into the nanocellulose suspension, the mixture was stirred at $70{ }^{\circ} \mathrm{C}$ for $2 \mathrm{~h}$, adding ammonia water to adjust the $\mathrm{pH}$ to above 10.5. After this, the resulting suspension stood for $48 \mathrm{~h}$, it was filtered, and the obtained cake was washed with water and ethanol, respectively. The filtered cake was freeze-dried for $24 \mathrm{~h}$, then ground to obtain NCC/HAP powder. A schematic diagram of NCC/HAP preparation is given in Figure 1. According to the above experimental procedure, NCC/HAP powders with different ratios were prepared respectively, as shown in Table 1.

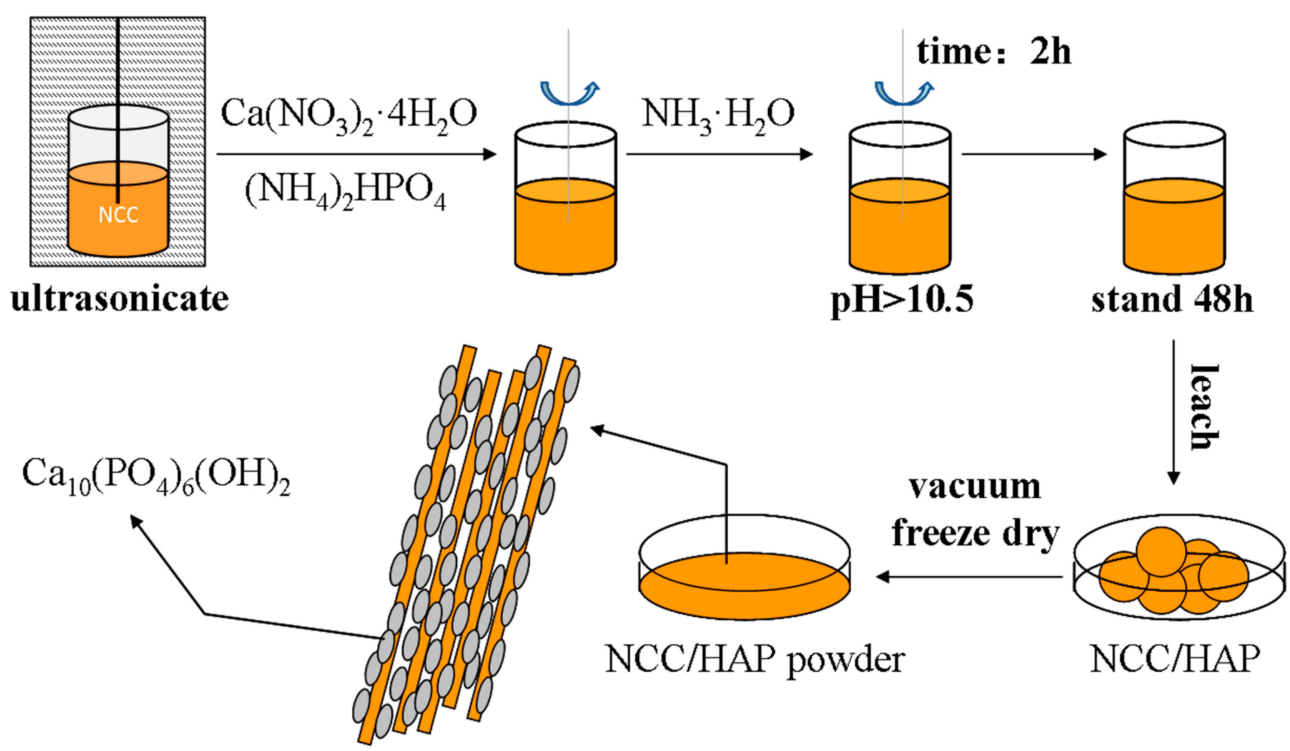

Figure 1. Schematic diagram of nanocellulose/hydroxyapatite (NCC/HAP) preparation.

Table 1. Chemical composition ratio for NCC/HAP preparation.

\begin{tabular}{ccccc}
\hline Group & $\mathbf{N C C}(\mathbf{g})$ & $\mathbf{C a}\left(\mathbf{N O}_{3}\right)_{\mathbf{2}} \cdot \mathbf{4} \mathbf{H}_{\mathbf{2}} \mathbf{O}(\mathbf{g})$ & $\left.\mathbf{( N H}_{\mathbf{4}}\right)_{\mathbf{2}} \mathbf{H P O}_{\mathbf{4}} \mathbf{( g )}$ & Ratio \\
\hline $\mathrm{A} 1$ & 0.5 & 1.175 & 0.394 & $50 / 50$ \\
$\mathrm{~A} 2$ & 0.4 & 1.410 & 0.473 & $40 / 60$ \\
$\mathrm{~A} 3$ & 0.3 & 1.646 & 0.552 & $30 / 70$ \\
$\mathrm{~A} 4$ & 0.2 & 1.881 & 0.631 & $20 / 80$ \\
A5 & 0.1 & 2.117 & 0.710 & $10 / 90$ \\
\hline
\end{tabular}




\subsection{Preparation of PLA/NCC-HAP}

PLA and the NCC/HAP were each dried in a vacuum oven for $24 \mathrm{~h}$. NCC/HAP $(0.05 \mathrm{~g})$ was then weighed and thoroughly dispersed under ultrasound in chloroform. PLA (5 g) was dissolved in chloroform by magnetic stirring. The dispersed NCC/HAP chloroform suspension was added into the PLA chloroform solution. The suspension solution for PLA/NCC-HAP system was sequentially ultrasonicated, stirred, poured into a glass garden, dried at room temperature for $24 \mathrm{~h}$, then under vacuum at $40{ }^{\circ} \mathrm{C}$ for $12 \mathrm{~h}$ to obtain a PLA/NCC-HAP composite film. The composite film was subjected to a hot press forming at a temperature of $180^{\circ} \mathrm{C}$ under a force of $500 \mathrm{~kg}$ for $8 \mathrm{~min}$ to obtain dumb bell-shaped PLA/NCC-HAP composite films. The prepared PLA/NCC-HAP composite films with different ratios of NCC to HAP are shown in Section 2.3. The additional content of NCC or NCC/HAP in composites was $1 \%$ wt of PLA.

\subsection{Characterization}

The morphologies of NCC and NCC/HAP were observed using a JEM-2100 Transmission Electron Microscope (TEM).

A Nicolet In10MX/Nicolet 6700 Fourier infrared (FT-IR) microscopy spectrometer was used to analyze the chemical structure of the samples. Prior to testing, the powdered sample was mixed and ground with potassium bromide and then compressed into tablets on an infrared tablet press.

X-ray diffraction (XRD) characterization was carried out on a D/max-2550VB+/PC type $18 \mathrm{KW}$ target $X$-ray diffractometer. The test was performed using a $\mathrm{CuK} \alpha(\lambda=0.154 \mathrm{~nm})$ light source, with diffraction angle $5-50^{\circ}$ and a scanning rate $5^{\circ} \cdot \mathrm{min}^{-1}$.

The tensile test of the dumb bell-shaped PLA/NCC-HAP composite films was determined with an Instron universal material testing machine. And the fractured surface of PLA/NCC-HAP was examined by using an S-4800 Field Emission Scanning Electron Microscope (SEM) coupled with Energy Dispersive Spectrometer (EDS).

Differential scanning calorimetry (DSC) of PLA/NCC-HAP samples was performed on a Q20 differential scanning calorimeter (conventional, of American TA Corporation). The test conditions were as follows: heating to $180{ }^{\circ} \mathrm{C}$ from $30^{\circ} \mathrm{C}$ at a heating rate of $10^{\circ} \mathrm{C} \cdot \mathrm{min}^{-1}$ under nitrogen atmosphere, holding for $5 \mathrm{~min}$, then cooling to $30^{\circ} \mathrm{C}$ at a rate of $10^{\circ} \mathrm{C} \cdot \mathrm{min}^{-1}$, then raising to $180{ }^{\circ} \mathrm{C}$ at a rate of $10{ }^{\circ} \mathrm{C} \cdot \mathrm{min}^{-1}$.

The thermal stability of PLA/NCC-HAP samples was tested on a Q500IR Thermal Gravimetric Analyzer (TGA) of American TA Company. The samples were heated from $40{ }^{\circ} \mathrm{C}$ to $700{ }^{\circ} \mathrm{C}$ at a rate of $20^{\circ} \mathrm{C} \cdot \mathrm{min}^{-1}$ under nitrogen atmosphere.

\section{Results}

\subsection{Characterization of NCC/HAP}

\subsubsection{Morphology of NCC/HAP}

In order to clarify the dispersity of the HAP in NCC, the surface morphologies of NCC and NCC/HAP were observed using TEM. The results are shown in Figure 2. Since NCC is one of the nanomaterials, it is easy to agglomerate in dispersion. However, it has been found that NCC still exhibited a rod-like structure. As can be seen from Figure 2a, the prepared NCC has a length of ca. $300 \mathrm{~nm}$ and a diameter of $\sim 30 \mathrm{~nm}$. Moreover, from the TEM images in Figure 2b-f, NCC/HAP with different ratios of NCC to HAP still maintained a rod-like structure. There were accumulated substances on the surface, which increased the diameter. These phenomena suggest that HAP disperses on the surface of the NCC. However, since the concentration of the dispersion was high when preparing samples for TEM testing, agglomeration occurred as seen in Figure $2 b-f$. 

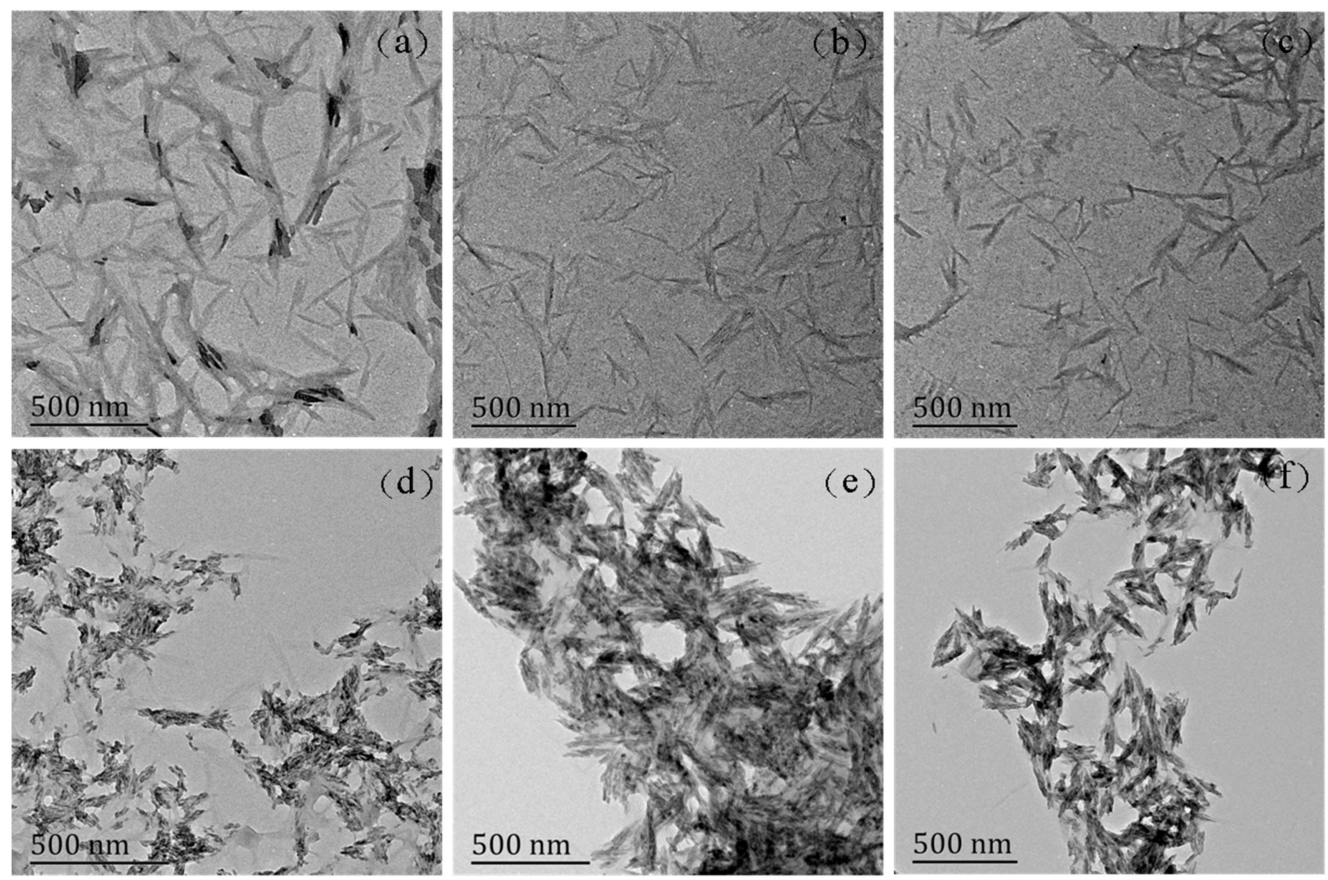

Figure 2. Transmission Electron Microscope (TEM) micrographs of NCC (a), NCC/HAP50/50 (b), NCC/HAP40/60 (c), NCC/HAP30/70 (d), NCC/HAP20/80 (e) and NCC/HAP10/90 (f).

\subsubsection{FT-IR of NCC/HAP}

Infrared spectroscopy was used to analyze the structural changes before and after nanocellulose modification. The infrared spectra of NCC and different proportions of NCC/HAP are shown in Figure 3. For NCC, the absorption peak of $3439 \mathrm{~cm}^{-1}$ is attributed to intramolecular hydrogen bond stretching and peak of $1630 \mathrm{~cm}^{-1}$ is assigned to $\mathrm{O}-\mathrm{H}$ bending due to adsorption of water [43]. The peaks around $2900 \mathrm{~cm}^{-1}$ and $2850 \mathrm{~cm}^{-1}$ correspond to the $-\mathrm{CH}_{2}$ and $-\mathrm{CH}_{3}$ aliphatic groups. The absorption peak of $1431 \mathrm{~cm}^{-1}$ is attributed to $\mathrm{CH}_{2}$ shearing motion in cellulose and peak of $1099 \mathrm{~cm}^{-1}$ is assigned to stretching vibration of $\mathrm{C}-\mathrm{O}[44,45]$. It can be seen that NCC/HAP has above the same peaks as NCC, while the broad peak around $1100-1000 \mathrm{~cm}^{-1}$ also corresponds to phosphoric acid group $\mathrm{PO}_{4}{ }^{3-}$ stretching vibration. In addition, peaks at $877 \mathrm{~cm}^{-1}$ and $1420-1480 \mathrm{~cm}^{-1}$, correspond to the $\mathrm{CO}_{3}{ }^{2-}$ band [46].

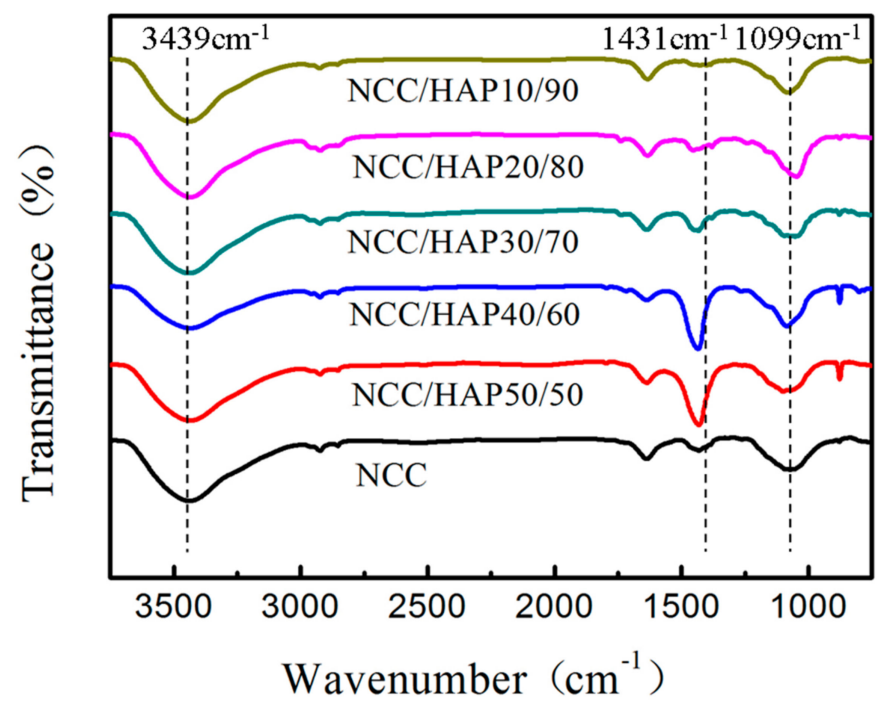

Figure 3. Fourier infrared (FT-IR) spectra of NCC, NCC/HAP50/50, NCC/HAP40/60, NCC/HAP30/70, NCC/HAP20/80 and NCC/HAP10/90. 


\subsubsection{X-Ray Diffraction of NCC/HAP}

The NCC and NCC/HAP structure was further characterized by XRD spectroscope and the results are shown in Figure 4. The XRD patterns exhibited diffraction peaks of NCC at $2 \theta$ values of $16.5^{\circ}$, $22.8^{\circ}$, attributed to plane (110), (200), which prove the cellulose I structure. With the increase of the HAP ratio, the diffraction peaks around $16.5^{\circ}$, and $22.8^{\circ}$ gradually disappeared. For NCC/HAP, peaks at $2 \theta$ values of $25.5^{\circ}, 32.1^{\circ}, 32.5^{\circ}, 40.0^{\circ}, 47.1^{\circ}$ correspond to (002), (210), (211), (310) and (222) lattice planes of HAP, respectively [47-49].

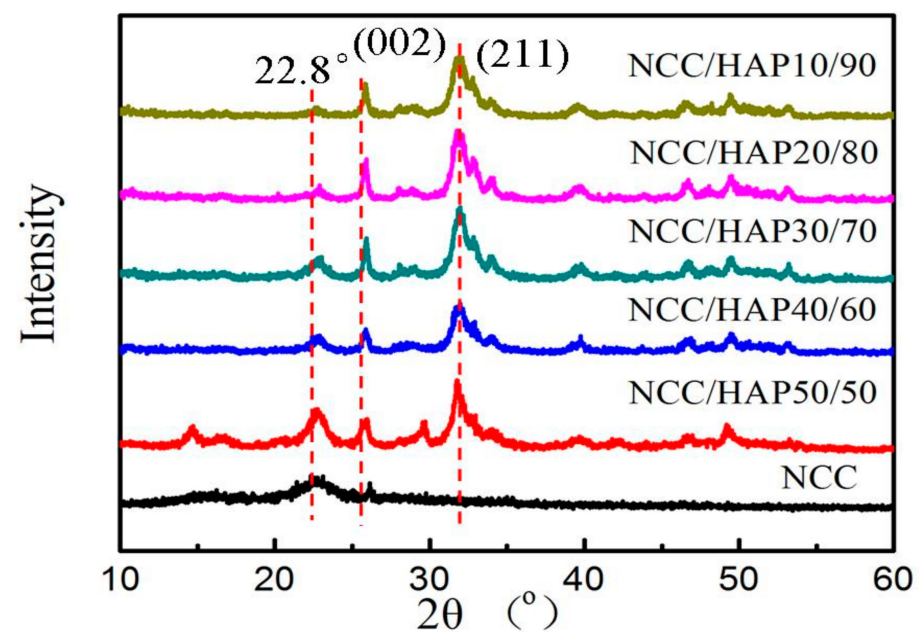

Figure 4. X-ray diffraction (XRD) of NCC, NCC/HAP50/50, NCC/HAP40/60, NCC/HAP30/70, NCC/HAP20/80 and NCC/HAP10/90.

\subsection{Performance of PLA/NCC-HAP Composite Films}

\subsubsection{FT-IR of PLA/NCC-HAP}

In order to investigate the chemical structure of the composite, the FT-IR spectra were recorded for PLA, PLA/NCC and PLA/NCC-HAP with different ratios of NCC to HAP. The results are shown in Figure 5. There was no obvious difference among these samples. FT-IR spectra of pure PLA and modified PLA (PLA/NCC and PLA/NCC-HAP) display a similar characteristic peak at $1750 \mathrm{~cm}^{-1}$ which is attributed to carbonyl groups $(\mathrm{C}=\mathrm{O})$ from all the PLA-based nanocomposites [50].

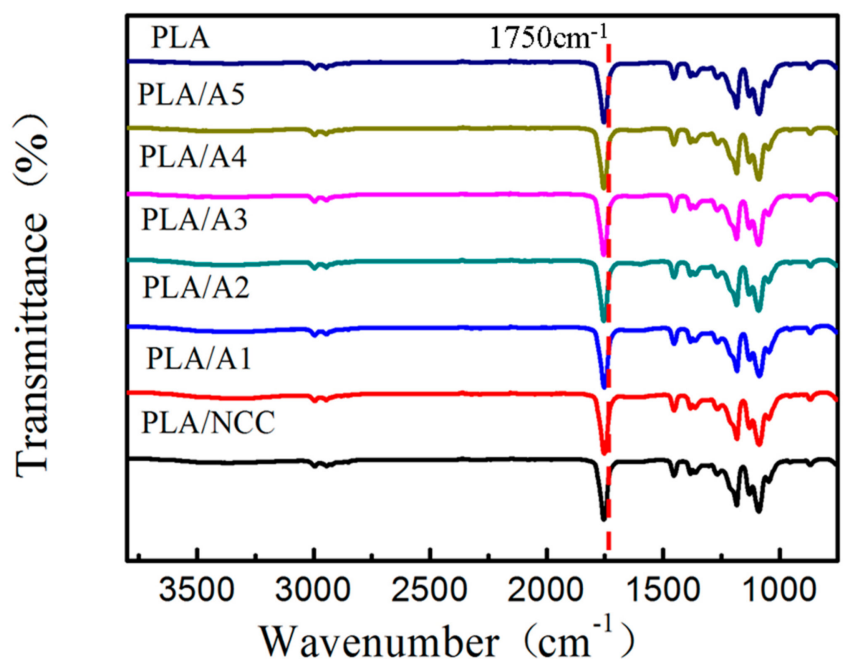

Figure 5. FTIR spectra of polylactic acid (PLA), PLA/NCC and PLA/NCC-HAP with different ratios of NCC to HAP. 


\subsubsection{X-Ray Diffraction of PLA/NCC-HAP}

XRD analysis of PLA, PLA/NCC and PLA/NCC-HAP was carried out in order to determine the crystalline structure. The results are given in Figure 6. Obviously, there are no significant diffraction peaks in pure PLA, due to its slow crystallization rate during molding, which resulted in an amorphous state. For the nanocomposites, the diffraction signals are masked by PLA owing to the low NCC and NCC/HAP content [51]. Moreover, there are no new uncharacteristic diffraction peaks found, which suggests that incorporation of NCC and NCC/HAP does not change the crystal structure of PLA [52].

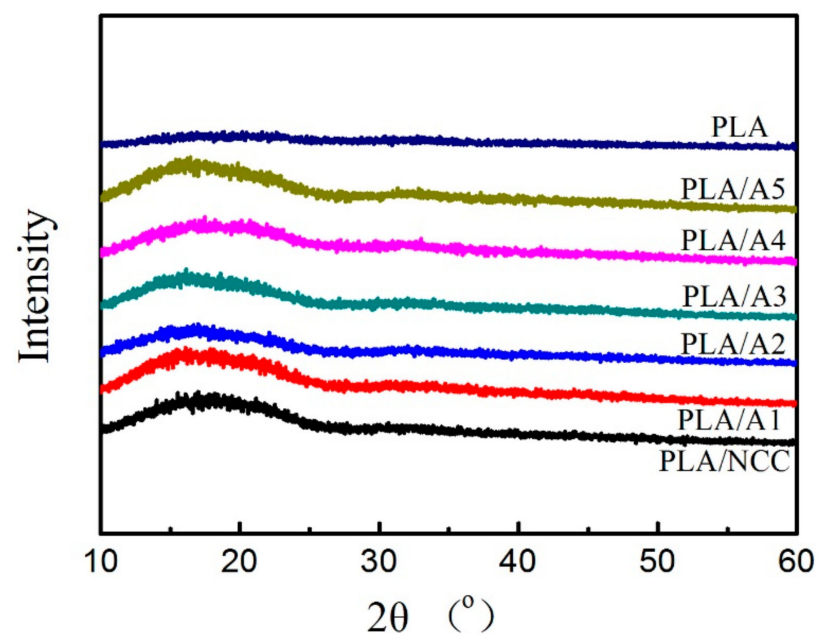

Figure 6. XRD characteristics PLA, PLA/NCC and PLA/NCC-HAP with different ratios of NCC to HAP.

\subsubsection{Mechanical Properties of PLA/NCC-HAP}

The influence of NCC/HAP on the mechanical properties of the nanocomposite films was studied as displayed in Figure 7. The results show that PLA/A3 (NCC:HAP $=30 / 70)$ had the highest tensile strength of $45.6 \mathrm{MPa}$ with a correspondingly high tensile modulus of 2.34 GPa. However, for PLA/NCC and PLA/A5 composite films, the tensile strengths decreased lower than that of pure PLA. This can be attributed to the limited compatibility of pristine PLA (it is hydrophobic) and NCC (it is hydrophilic). Additionally, when the ratio of NCC to HAP is too small (A5, NCC:HAP = 10/90), the composite films show poor compatibility. A suitable ratio of NCC/HAP improved the mechanical properties of the composite films, due to strong hydrogen bonding interaction at the interface, leading to good NCC/HAP dispersion in the PLA matrix [53].
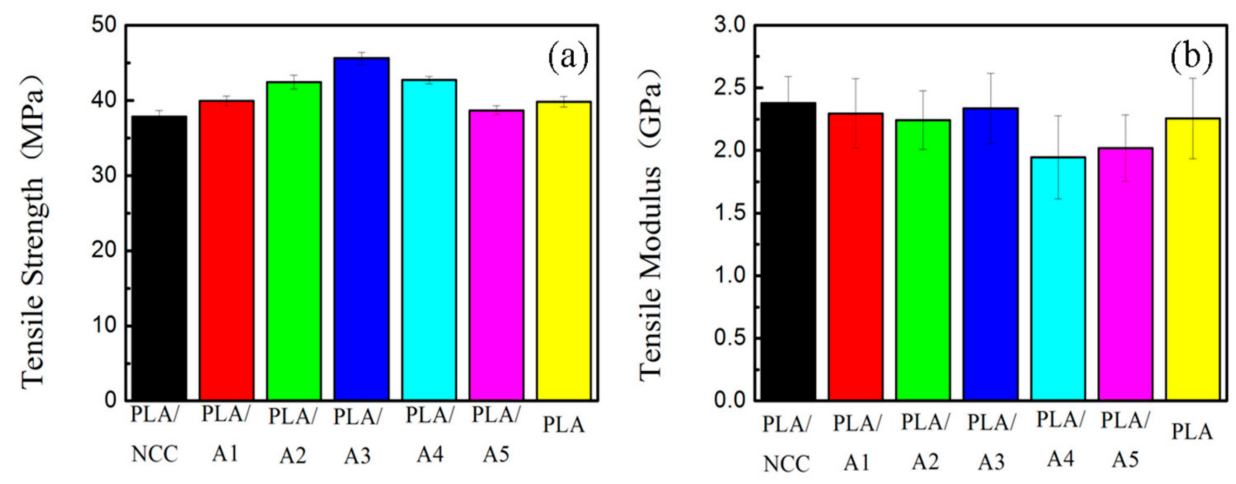

Figure 7. Mechanical properties of PLA/NCC-HAP films with different ratios of NCC to hydroxyapatite (HAP): (a) tensile strength and (b) tensile modulus. 
In order to explore the effect of NCC/HAP on the toughness of the nanocomposite, the elongation at break of samples is given in Figure 8. The results show that PLA/A3 (NCC:HAP = 30/70) had the maximum tensile strength and its elongation was only $2.08 \%$. Combined with the above results of tensile modulus, the elongation at break of the samples has a negative correlation with the tensile modulus.

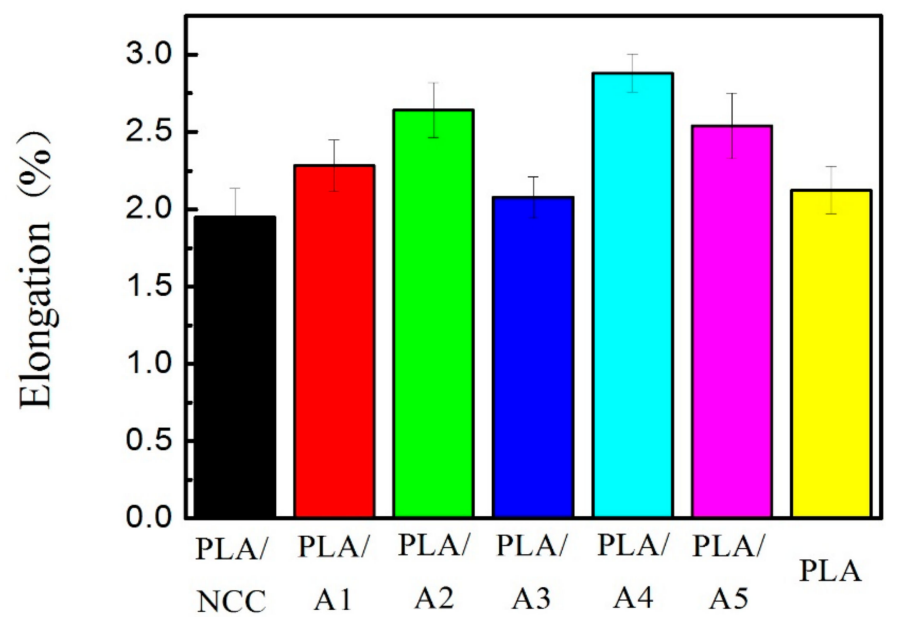

Figure 8. Elongation at break of PLA/NCC-HAP films with different ratios of NCC to HAP.

\subsubsection{SEM of PLA/NCC-HAP Fractured Surface}

In order to understand the relationship between the mechanical properties and the detailed structures, SEM micrographs of the fractured surfaces of the PLA/NCC-HAP composite films were carried out as presented in Figure 9. The pristine PLA fractured surface exhibits a smooth braided section, which indicates that the PLA is prone to brittle fracture. After the addition of NCC, the poor dispersion of PLA/NCC composites showed agglomeration and distinct cellulose rod-like structure. As the NCC/HAP added, the brittle fracture of PLA changes to a plastic fracture. When the ratio of NCC to HAP was 40/60 (A2) and 30/70 (A3), the fracture surface of the composite material showed a spurt-like surface with the voids caused by the extraction of cellulose nanorods, which indicated that the NCC-HAP interacted with the PLA matrix. It was also consistent with the increase in tensile strength $[54,55]$.
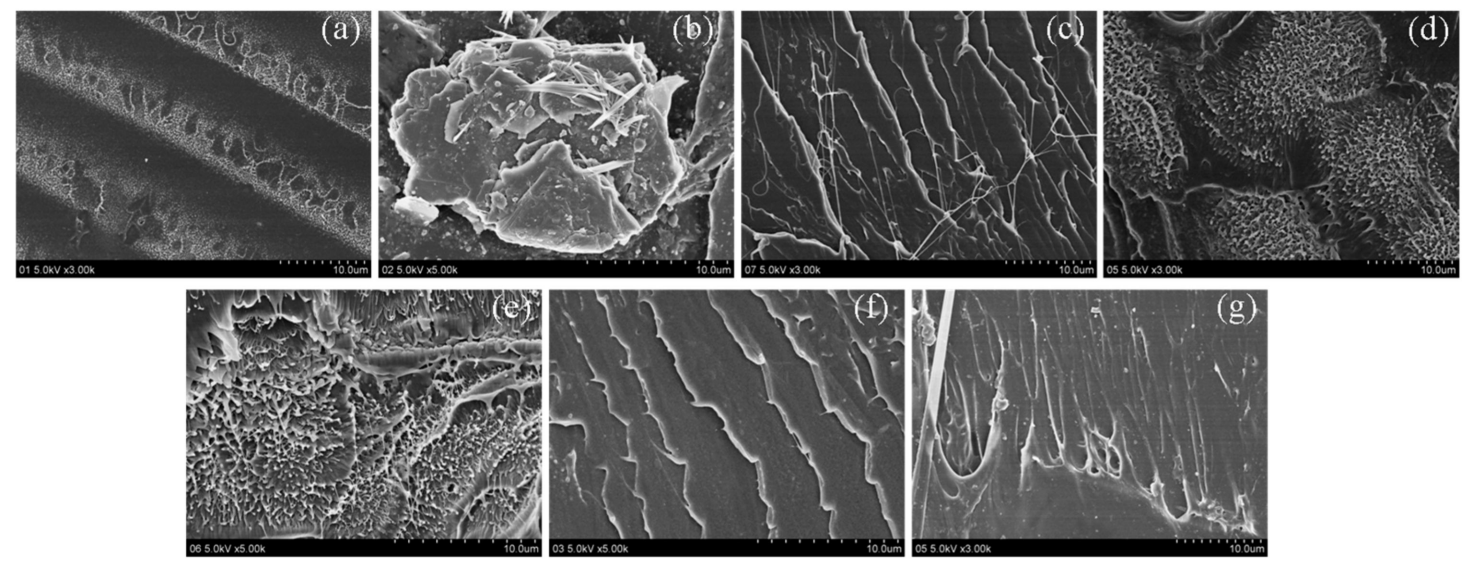

Figure 9. Scanning Electron Microscope (SEM) images of the fractured surfaces after tensile testing:
(a) PLA, (b) PLA/NCC,
(c) PLA/A1, (d)
(d) PLA/A2,
(e) PLA/A3, (f) PLA/A4 and (g) PLA/A5.

In order to illustrate the distribution of main elements (Ca and $\mathrm{P}$ ) at the cross section of the composites, the EDS results are shown in Figure 10. It can be seen that both Ca and P are uniformly distributed in the PLA/NCC-HAP composite films. 


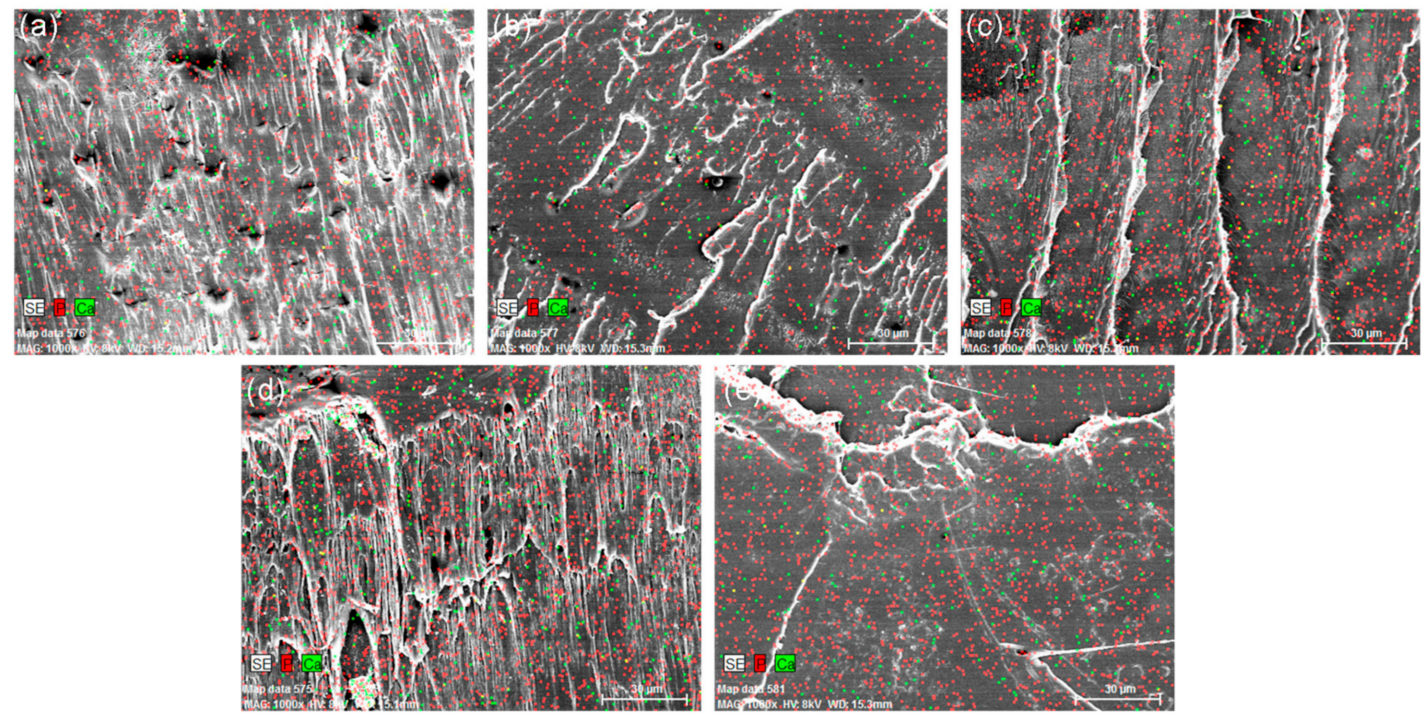

Figure 10. Energy Dispersive Spectrometer (EDS) of (a) PLA/A1, (b) PLA/A2, (c) PLA/A3, (d) PLA/A4, (e) PLA/A5.

\subsubsection{DSC Characterization of PLA/NCC-HAP}

The thermal behavior of PLA, PLA/NCC and PLA/NCC-HAP composites was determined by DSC, shown in Figure 11. The $\mathrm{T}_{\mathrm{g}}$ of pure PLA is about $62.6^{\circ} \mathrm{C}$, and the addition of NCC/HAP shifted the $\mathrm{T}_{\mathrm{g}}$ to the low temperature direction. The $\mathrm{T}_{\mathrm{g}}$ of the PLA/NCC-HAP composite was slightly lower than $61{ }^{\circ} \mathrm{C}$, indicating that NCC/HAP enhanced the compatibility with the PLA matrix. However, the $\mathrm{T}_{\mathrm{g}}$ of PLA/NCC composites increased slightly, to about $63^{\circ} \mathrm{C}$. This indicates that the compatibility between NCC and PLA was not good, which was consistent with the above mechanical property results. Also, there was no crystalline peak and melting peak in DSC curves, suggesting that PLA, PLA/NCC and PLA/NCC-HAP composites in amorphous state have low crystallinity degrees, which is consistent with the observation claimed from XRD characterization results [56,57].

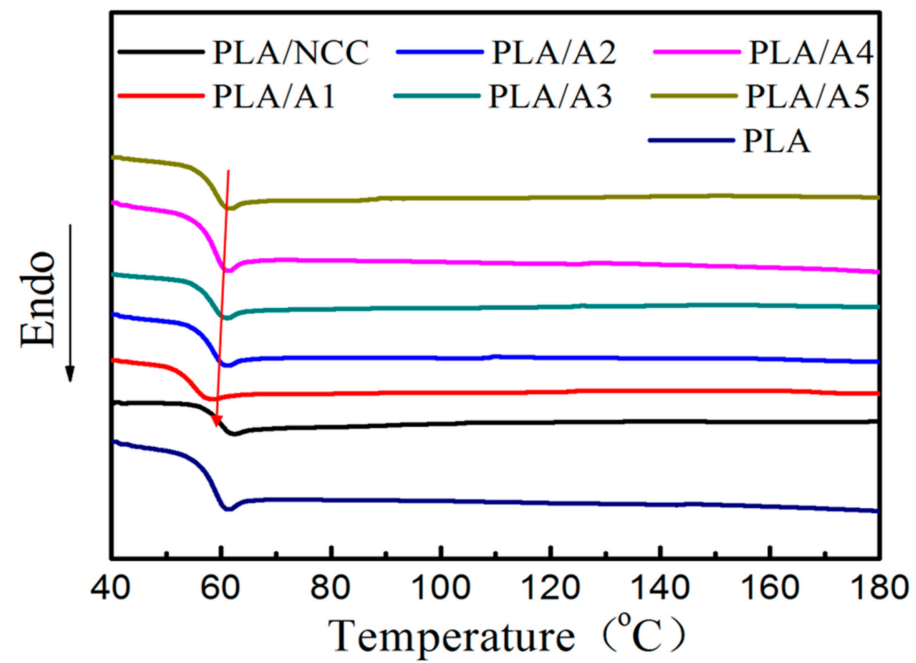

Figure 11. Differential scanning calorimetry (DSC) curves of PLA, PLA/NCC and PLA/NCC-HAP with different ratios of NCC to HAP.

\subsubsection{TGA Characterization of PLA/NCC-HAP}

To explore the thermal stability of the composite, the TGA curves for PLA, PLA/NCC and PLA/NCC-HAP composites were obtained as shown in Figure 12. The initial thermal decomposition 
temperature $\left(\mathrm{T}_{10 \%}\right)$ of pure PLA thermal degradation was about $340.1^{\circ} \mathrm{C}$. There was no change in the thermal stability for PLA/NCC, PLA/A1, PLA/A5 composites. However, the addition of other ratios of NCC/HAP nanoparticles had a positive effect on the thermal stability of the composite. When the ratio of NCC to HAP was 40/60 (A2), 30/70 (A3) and 20/80 (A4), the $\mathrm{T}_{10 \%}$ of the composite was higher than $340.1{ }^{\circ} \mathrm{C}$. This can be attributed to the interaction between NCC-HAP and PLA, hindering chain movement and inhibiting chain melting during the degradation process [58,59].

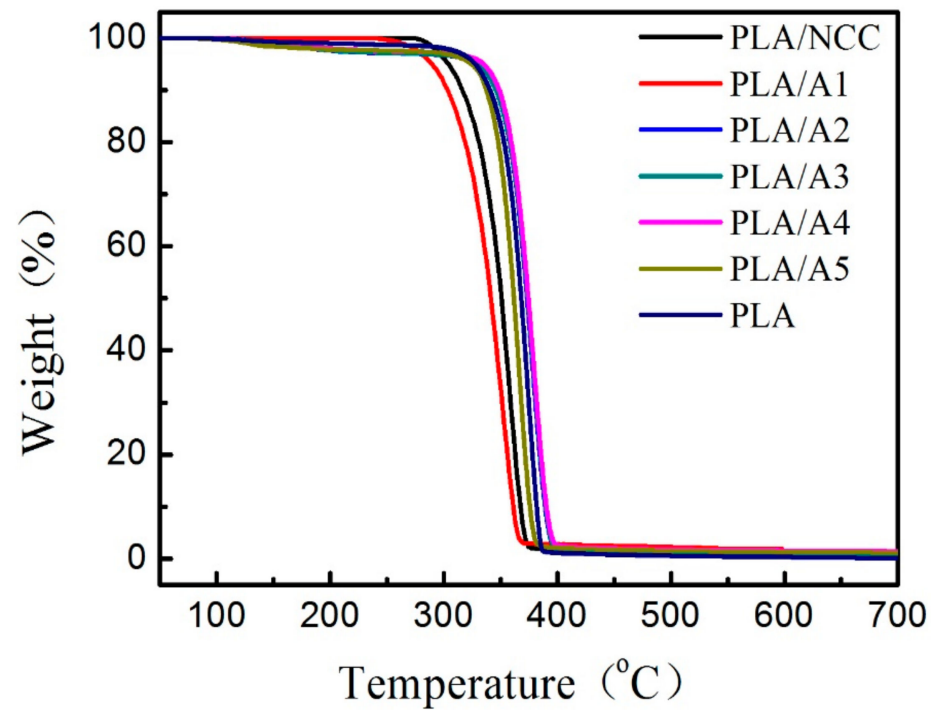

Figure 12. Thermal Gravimetric Analyzer (TGA) curves of PLA, PLA/NCC and PLA/NCC-HAP with different ratios of NCC to HAP.

\section{Conclusions}

A series of NCC/HAP with different ratios were prepared to reinforce the PLA matrix. The thermal stabilities and mechanical properties of the obtained PLA/NCC-HAP composites were systematically investigated. In previous reports, the addition of inorganic nanoparticles resulted in a decrease in the tensile strength properties of the composite. Whilst here, the tensile strength, tensile modulus and thermal stability of the PLA/NCC-HAP composites significantly increased, especially for sample PLA/A3 (NCC/HAP at a ratio of 30/70). However, the addition of NCC/HAP does not accelerate the crystallization and neither improves the crystallinity degree of PLA. The above results show that NCC/HAP is a good reinforcing material for PLA. Since HAP is a bioceramic material with good osteoconductivity and osteoinductivity, the obtained PLA/NCC-HAP composite may be a promising medical repair or replacement material.

Author Contributions: Conceptualization, J.L., C.S., H.Z. and M.Y.; methodology, H.Z. and M.Y. validation, K.Y. and K.W.; formal analysis, J.L.; investigation, J.L., Y.J., Y.Y. and F.F.; data curation, J.L. and C.S.; writing-original draft preparation, J.L.; writing-review and editing, R.T., Z.S., Y.L., H.Z. and K.H.; visualization, J.L. and C.S.; supervision, Z.S., Y.L. and K.H.; project administration, H.Z.; funding acquisition, M.Y.

Funding: This work was supported by the National Key Research and Development Program of China (No. 2017YFB0309300) and the "Fundamental Research Funds for the Central Universities" (No. 16D110623, 18D110622). Zhang would like to appreciate the financial support of Shanghai Science and Technology Committee (No. 18DZ1101003).

Conflicts of Interest: The authors declare no conflict of interest.

\section{References}

1. Castro-Aguirre, E.; Iñiguez-Franco, F.; Samsudin, H.; Fang, X.; Auras, R. Poly(lactic acid)-mass production, processing, industrial applications, and end of life. Adv. Drug Deliv. Rev. 2016, 107, 333-366. [CrossRef] [PubMed] 
2. Shady, F.; Daniel, G.A.; Robert, L. Physical and mechanical properties of PLA, and their functions in widespread applications-A comprehensive review. Adv. Drug Deliv. Rev. 2016, 107, 367-392.

3. Singhvi, M.S.; Zinjarde, S.S.; Gokhale, D.V. Poly-lactic acid (PLA): Synthesis and biomedical applications. J. Appl. Microbiol. 2019. [CrossRef] [PubMed]

4. Murphy, C.A.; Collins, M.N. Microcrystalline Cellulose reinforced polylactic acid biocomposite filaments for 3D printing. Polym. Compos. 2016, 39, 1311-1320. [CrossRef]

5. Julia, P.; Stanislaw, S.; Stanislaw, P. Polylactides-methods of synthesis and characterization. Adv. Drug Deliv. Rev. 2016, 107, 3-16.

6. Jiang, M.Q.; Liu, Y.; Cheng, C.; Zhou, J.L.; Liu, B.H.; Yu, M.H.; Zhang, H. Enhanced mechanical and thermal properties of monocomponent high performance epoxy resin by blending with hydroxyl terminated polyethersulfone. Polym. Test. 2018, 69, 302-309. [CrossRef]

7. Sun, Z.Y.; Xu, L.; Chen, Z.G.; Wang, Y.H.; Rogers, T.; Cheng, C.; Zhou, S.; Liu, Y.; Yu, M.H.; Zhang, H. Enhancing the mechanical and thermal properties of epoxy resin via blending with thermoplastic polysulfone. Polymers 2019, 11, 461. [CrossRef] [PubMed]

8. Zhou, S.; Chen, Z.G.; Roger, T.; Cheng, C.; Sun, Z.Y.; Xu, L.; Liu, Y.; Jiang, M.Q.; Zhou, J.L.; Zhang, H.; et al. Highly improving the mechanical and thermal properties of epoxy resin via blending with polyetherketone cardo. Compos. Commun. 2019, 13, 80-84. [CrossRef]

9. Marius, M.; Philippe, D. PLA composites: From production to properties. Adv. Drug Deliv. Rev. 2016, $107,17-46$.

10. Klemm, D.; Heublein, B.; Fink, H.P.; Bohn, A. Cellulose: Fascinating biopolymer and sustainable raw material. Angew. Chem. Int. Ed. 2005, 44, 3358-3393. [CrossRef]

11. Klemm, D.; Cranston, E.D.; Fischer, D.; Gama, M.; Kedzior, S.A.; Kralisch, D.; Kramer, F.; Kondo, T.; Lindström, T.; Nietzsche, S.; et al. Nanocellulose as a natural source for groundbreaking applications in materials science: Today's state. Mater. Today 2018, 21, 720-748. [CrossRef]

12. Sharma, P.R.; Joshi, R.; Sharma, S.K.; Hsiao, B.S. A simple approach to prepare carboxycellulose nanofibers from untreated biomass. Biomacromolecules 2017, 18, 2333-2342. [CrossRef] [PubMed]

13. Sharma, P.R.; Zheng, B.; Sharma, S.K.; Zhan, C.; Wang, R.; Bhatia, S.R.; Hsiao, B.S. High aspect ratio carboxycellulose nanofibers prepared by nitro-oxidation method and their nanopaper properties. ACS Appl. Nano Mater. 2018, 1, 3969-3980. [CrossRef]

14. Sharma, P.R.; Varma, A.J. Functional nanoparticles obtained from cellulose: Engineering the shape and size of 6-carboxycellulose. Chem. Commun. 2013, 49, 8818-8820. [CrossRef] [PubMed]

15. Hosseinmardi, A.; Annamalai, P.K.; Wang, L.; Martin, D.; Amiralian, N. Reinforcement of natural rubber latex using lignocellulosic nanofibers isolated from spinifex grass. Nanoscale 2017, 9, 9510-9519. [CrossRef] [PubMed]

16. Sharma, P.R.; Aurnov Chattopadhyay, A.; Sharma, S.K.; Geng, L.; Amiralian, N.; Martin, D.; Hsiao, B.S. Nanocellulose from spinifex as an effective adsorbent to remove cadmium(II) from water. ACS Sustain. Chem. Eng. 2018, 6, 3279-3290. [CrossRef]

17. Sharma, P.R.; Chattopadhyay, A.; Zhan, C.; Sharma, S.K.; Geng, L.; Hsiao, B.S. Lead removal from water using carboxycellulose nanofibers prepared by nitro-oxidation method. Cellulose 2018, 25, 1961-1973. [CrossRef]

18. Sharma, P.R.; Chattopadhyay, A.; Sharma, S.K.; Hsiao, B.S. Efficient removal of UO2 ${ }^{2+}$ from water using carboxycellulose nanofibers prepared by the nitro-oxidation method. Ind. Eng. Chem. Res. 2017, 56, 13885-13893. [CrossRef]

19. Sharma, P.R.; Sharma, S.K.; Antoine, R.; Hsiao, B.S. Efficient removal of arsenic using zinc oxide nanocrystal-decorated regenerated microfibrillated cellulose scaffolds. ACS Sustain. Chem. Eng. 2019, 7,6140-6151. [CrossRef]

20. Musa, R.K.; Vahid, K. Effect of cellulose nanocrystals (CNC) on rheological and mechanical properties and crystallization behavior of PLA/CNC nanocomposites. Carbohydr. Polym. 2015, 123, 105-114.

21. Zhang, Y.C.; Wu, J.; Wang, B.J.; Sui, X.F.; Zhong, Y.; Zhang, L.P.; Mao, Z.P.; Xu, H. Cellulose nanofibril-reinforced biodegradable polymer composites obtained via a Pickering emulsion approach. Cellulose 2017, 24, 3313-3322. [CrossRef]

22. Jonoobi, M.; Harun, J.; Mathew, A.P.; Oksman, K. Mechanical properties of cellulose nanofiber (CNF) reinforced polylactic acid (PLA) prepared by twin screw extrusion. Compos. Sci. Technol. 2010, 70, 1742-1747. [CrossRef] 
23. Kale, R.D.; Gorade, V.G.; Madye, N.; Chaudhary, B.; Bangde, P.S.; Dandekar, P.P. Preparation and characterization of biocomposite packaging film from poly (lactic acid) and acylated microcrystalline cellulose using rice bran oil. Int. J. Biol. Macromol. 2018, 118, 1090-1102. [CrossRef] [PubMed]

24. Eduardo, R.; Iñaki, U.; Jalel, L.; Luis, S. Surface-modified nano-cellulose as reinforcement in poly (lactic acid) to conform new composites. Ind. Crops Prod. 2015, 71, 44-53.

25. Li, L.; Bao, R.Y.; Gao, T.; Liu, Z.Y.; Xie, B.H.; Yang, M.B.; Yang, W. Dopamine-induced functionalization of cellulose nanocrystals with polyethylene glycol towards poly(L-lactic acid) bionanocomposites for green packaging. Carbohydr. Polym. 2019, 203, 275-284. [CrossRef] [PubMed]

26. Nair, S.S.; Chen, H.Y.; Peng, Y.; Huang, Y.H.; Yan, N. Polylactic acid biocomposites reinforced with nanocellulose fibrils with high lignin content for improved mechanical, thermal, and barrier properties. ACS Sustain. Chem. Eng. 2018, 6, 10058-10068. [CrossRef]

27. Le, D.; Kongparakul, S.; Samart, C.; Phanthong, P.; Karnjanakom, S.; Abudula, A.; Guan, G.Q. Preparing hydrophobic nanocellulose-silica film by a facile one-pot method. Carbohydr. Polym. 2016, 153, 266-274. [CrossRef] [PubMed]

28. Fedorova, P.P.; Luginina, A.A.; Kuznetsov, S.V.; Voronov, V.V.; Lyapin, A.A.; Ryabochkina, P.A.; Chernov, M.V.; Mayakova, M.N.; Pominova, D.V.; Uvarov, O.V.; et al. Preparation and properties of methylcellulose/nanocellulose/ $\mathrm{CaF}_{2}$ : Hopolymer-inorganic composite films for two-micron radiation visualizers. J. Fluor. Chem. 2017, 202, 9-18. [CrossRef]

29. Faranak, M.; Marisa, F.; Nereida, C. In Situ biosynthesis of bacterial nanocellulose-CaCO $\mathrm{CO}_{3}$ hybrid bionanocomposite: One-step process. Mater. Sci. Eng. C 2016, 65, 393-399.

30. Zhang, X.W.; Sun, H.Y.; Tan, S.N.; Gao, J.; Fu, Y.J.; Liu, Z.G. Hydrothermal synthesis of Ag nanoparticles on the nanocellulose and their antibacterial study. Inorg. Chem. Commun. 2019, 100, 44-50. [CrossRef]

31. Hyeong, Y.C.; Young, G.J. Microstructures and piezoelectric performance of eco-friendly composite films based on nanocellulose and barium titanate nanoparticle. Compos. Part B Eng. 2019, 168, 58-65.

32. Song, H.Z.; Luo, Z.Q.; Wang, C.Z.; Hao, X.F.; Gao, J.G. Preparation and characterization of bionanocomposite fiber based on cellulose and nano-SiO 2 using ionic liquid. Carbohydr. Polym. 2013, 98, 161-167. [CrossRef] [PubMed]

33. Matthew, D.; Gawryla, O.B.; Christoph, W.; David, A.S. Clay aerogel/cellulose whisker nanocomposites: A nanoscale wattle and daub. J. Mater. Chem. 2009, 19, 2118-2124.

34. Mahmoudian, S.; Wahit, M.U.; Ismail, A.F.; Balakrishnan, H.; Imran, M. Bionanocomposite fibers based on cellulose and montmorillonite using ionic liquid 1-ethyl-3-methylimidazolium acetate. J. Mater. Sci. 2015, 50, 1228-1236. [CrossRef]

35. Garusinghe, M.U.; Varanasi, S.; Raghuwanshi, V.S.; Garnier, G.; Batchelor, W. Nanocellulose-montmorillonite composites of low water vapour permeability. Colloids Surf. A 2018, 540, 233-241. [CrossRef]

36. Zhang, H.; Wang, Z.G.; Zhang, Z.N.; Wu, J.; Zhang, J.; He, J.S. Regenerated-cellulose/ multiwalled-carbon-nanotube composite fibers with enhanced mechanical properties prepared with the ionic liquid 1-allyl-3-methylimidazolium chloride. Adv. Mater. 2007, 19, 698-704. [CrossRef]

37. Liu, P.; Zhu, C.T.; Mathew, A.P. Mechanically robust high flux graphene oxide-nanocellulose membranes for dye removal from water. J. Hazard. Mater. 2019, 371, 484-493. [CrossRef]

38. Hokkanen, S.; Bhatnagar, A.; Srivastava, V.; Suorsa, V.; Sillanpää, M. Removal of $\mathrm{Cd}^{2+}, \mathrm{Ni}^{2+}$ and $\mathrm{PO}_{4}{ }^{3-}$ from aqueous solution by hydroxyapatite-bentonite clay-nanocellulose composite. Int. J. Biol. Macromol. 2018, 118, 903-912. [CrossRef]

39. Niamsap, T.; Lam, N.T.; Sukyai, P. Production of hydroxyapatite-bacterial nanocellulose scaffold with assist of cellulose nanocrystals. Carbohydr. Polym. 2019, 205, 159-166. [CrossRef]

40. Ishikawa, M.; Oaki, Y.; Tanaka, Y.; Kakisawa, H.; Salazar, A.G.; Imai,H. Fabrication of nanocellulose-hydroxyapatite composites and their application as water-resistant transparent coatings. J. Mater. Chem. B 2015, 3, 5858-5863. [CrossRef]

41. Gong, M.; Zhao, Q.; Dai, L.M.; Li, Y.Y.; Jiang, T.S. Fabrication of polylactic acid/hydroxyapatite/graphene oxide composite and their thermal stability, hydrophobic and mechanical properties. J. Asian Ceram. Soc. 2017, 5, 160-168. [CrossRef]

42. Kumar, A.; Negi, Y.S.; Choudhary, V.; Bhardwaj, N.K. Characterization of cellulose nanocrystals produced by acid-hydrolysis from sugarcane bagasse as agro-waste. J. Mater. Phys. Chem. 2014, 2, 1-8. 
43. Troedec, M.L.; Sedan, D.; Peyratout, C.; Bonnet, J.P.; Smith, A.; Guinebretiere, R.; Gloaguen, V.; Krausz, P. Influence of various chemical treatments on the composition and structure of hemp fibers. Compos. Part $A$ Appl. Sci. Manuf. 2008, 39, 514-522. [CrossRef]

44. Yuan, Z.Y.; Wen, Y.B. Enhancement of hydrophobicity of nanofibrillated cellulose through grafting of alkyl ketene dimmer. Cellulose 2018, 25, 6863-6871. [CrossRef]

45. Sonia, S.; Ana, C.; Abilio, S.; Rogerio, S. Poly (lactic acid)/cellulose films produced from composite spheres prepared by emulsion-solvent evaporation method. Polymers 2019, 11, 66.

46. Kumar, A.; Negi, Y.S.; Choudhary, V.; Bhardwaj, N.K. Fabrication of poly (vinyl alcohol)/ovalbumin/cellulose nanocrystals/nanohydroxyapatite based biocomposite scaffolds. Int. J. Polym. Mater. Polym. Biomater. 2016, 65, 191-201. [CrossRef]

47. Erin, M.S.; Robert, J.M.; Kyriaki, K. Processing and characterization of cellulose nanocrystals/polylactic acid nanocomposite films. Materials 2015, 8, 8106-8116.

48. Xie, Q.Z.; Wang, S.L.; Chen, X.; Zhou, Y.Y.; Fang, H.G.; Li, X.L.; Cheng, S.; Ding, Y.S. Thermal stability and crystallization behavior of cellulose nanocrystals and their poly(L-lactide) nanocomposites: Effects of surface ionic group and poly(D-lactide) grafting. Cellulose 2018, 25, 6847-6862. [CrossRef]

49. Kumar, A.; Negi, Y.S.; Choudhary, V.; Bhardwaj, N.K. Microstructural and mechanical properties of porous biocomposite scaffolds based on polyvinyl alcohol, nano-hydroxyapatite and cellulose nanocrystals. Cellulose 2014, 21, 3409-3426. [CrossRef]

50. Yu, H.Y.; Zhang, H.; Song, M.L.; Zhou, Y.; Yao, J.M.; Ni, Q.Q. From cellulose nanospheres, nanorods to nanofibers: Various aspect ratio induced nucleation/reinforcing effects on polylactic acid for robust-barrier food packaging. ACS Appl. Mater. Interfaces 2017, 9, 43920-43938. [CrossRef]

51. Lu, F.F.; Yu, H.Y.; Yan, C.F.; Yao, J.M. Polylactic acid nanocomposite films with spherical nanocelluloses as efficient nucleation agents: Effects on crystallization, mechanical and thermal properties. RSC Adv. 2016, 6, 46008-46018. [CrossRef]

52. Santos, F.A.; Iulianelli, G.C.V.; Tavares, M.I.B. Effect of microcrystalline and nanocrystals cellulose fillers in materials based on PLA matrix. Polym. Test. 2017, 61, 280-288. [CrossRef]

53. Park, J.W.; Shin, J.H.; Shim, G.S.; Sim, K.B.; Jang, S.W.; Kim, H.J. Mechanical strength enhancement of polylactic acid hybrid composites. Polymers 2019, 11, 349. [CrossRef]

54. Marina, R.A.; Tatiana, B.R.N.; Tayna, I.S.S.; Ingrid, L.L.; Leticia, A.P.R.; Joao, H.O.R.; Janice, I.D.; Bruna, A.S.M. Effect of cellulose nanocrystals from different lignocellulosic residues to chitosan/glycerol films. Polymers 2019, 11, 658 .

55. Anayet, K.; Matthew, J.D.; Bishnu, A.; Rabin, B.; Marya, A. Polymeric composites with embedded nanocrystalline cellulose for the removal of iron(II) from contaminated water. Polymers 2018, 10, 1377.

56. Chi, H.; Xue, J.; Zhang, C.; Chen, H.Y.; Li, L.; Qin, Y.Y. High pressure treatment for improving water vapour barrier properties of poly (lactic acid)/Ag nanocomposite films. Polymers 2018, 10, 1011. [CrossRef]

57. Wang, X.; Jia, Y.; Liu, Z.; Miao, J.J. Influence of the lignin content on the properties of poly (lactic acid)/lignin-containing cellulose nanofibrils composite films. Polymers 2018, 10, 1013. [CrossRef]

58. Khalili, P.; Liu, X.L.; Zhao, Z.R.; Blinzler, B. Fully biodegradable composites: Thermal, flammability, moisture absorption and mechanical properties of natural fibre-reinforced composites with nano-hydroxyapatite. Materials 2019, 12, 1145. [CrossRef]

59. Yaret, G.T.H.; Gloria, M.O.D.; Lucia, T.J.; Nayeli, S.C.J.; Alejandro, A.T.; Blanca, E.G.P.; Heberto, B.R. Biological compatibility of a polylactic acid composite reinforced with natural chitosan obtained from shrimp waste. Materials 2018, 11, 1465.

(C) 2019 by the authors. Licensee MDPI, Basel, Switzerland. This article is an open access article distributed under the terms and conditions of the Creative Commons Attribution (CC BY) license (http://creativecommons.org/licenses/by/4.0/). 